\title{
REFRACTION CORRECTION IN PRECISE LEVELING OBSERVATIONS FOR NATIONAL LEVELING NETWORK FIRST ORDER
}

\author{
Nikolay DIMITROV $\mathbb{D}^{*}$, Ivan GEORGIEV, Petar DANCHEV ${ }^{\circledR}$ \\ National Institute of Geophysics, Geodesy and Geography, Bulgarian Academy of Sciences, Sofia, Bulgaria
}

Received 18 November 2019; accepted 05 December 2020

\begin{abstract}
The paper deals with some problems when applying a correction to reduce the effect of vertical refraction in precise leveling observation. An example for calculating the refraction correction for one first order leveling line with length of $109 \mathrm{~km}$ in Bulgaria is given. Comparison between the obtained errors before and after applying refraction correction has been made. The results show that is important to measure the temperatures simultaneously with the leveling by aspiration thermometer with an accuracy of $\pm 0.1^{\circ} \mathrm{C}$. It is recommended to make experimental research and to adopt appropriate for Bulgaria model for taking into account the influence of vertical refraction.
\end{abstract}

Keywords: precise leveling, atmospheric refraction, national leveling network, leveling line, refraction correction, air temperature gradient.

\section{Introduction}

Atmospheric refraction is the deflection of light or other electromagnetic waves from the straight line due to the change in air density as a function of the height above the ground. Refraction is due to a reduction in the speed of light as the air layer density increases. As the leveling is performed near the ground surface, the results are significantly influenced from the ground atmosphere layer. In the leveling, the horizontal line of sight passes through different isothermal layers of air with different density. This leads to an error in read of fore and back rods. The error caused by refraction is generally considered to be a significant systematic error in the leveling measurements. In the far 1937, long before refraction was widely accepted as a major source of error, Professor T. J. Kukkamäki of the Finnish Geodetic Institute investigated this phenomenon and develop a mathematical model for correcting (reducing) its impact. He estimated a correction that is proportional to the difference in the measured two temperatures of air at heights of $0.5 \mathrm{~m}$ and $2.5 \mathrm{~m}$. Initially only a few countries apply this correction, but now when it is known that it is necessary, the correction is widely used, especially in countries located in the middle and lower latitudes.

\section{Theoretical background}

The refraction correction for geodetic leveling must be applied to each single set-up (Kukkamäki, 1939) and is given by:

$$
R=-2 \times 10^{-6} A(S / 50)^{2} \Delta t \Delta h,
$$

where: $S$ is the site length (in meters); $\Delta t=t 1-t 2$ is the temperature difference $\left({ }^{\circ} \mathrm{C}\right)$, calculated from the measured temperatures at two heights; $t 1$ - upper temperature and $t 2$ - lower temperature; $\Delta h$ measured difference of elevation in set-up (in meters); $A$ - a pre-determined coefficient. In a numerous of studies it's value is accepted as $A=$ 70 (Hytonen, 1967; Holdahl, 1981).

The temperature distribution model in the ground air layer is given by:

$$
T=a+b z^{c},
$$

where: $T$ - temperature $\left({ }^{\circ} \mathrm{C}\right)$ at a height $z$ above the ground surface; $a, b$ and $c$ are constants for any instant and vary with time.

The temperature model (2) is based on the following assumptions:

- The refraction coefficient of air depends mainly on temperature since the effect of humidity is negligibly small for optical propagation.

*Corresponding author. E-mail: ndimitrov@geophys.bas.bg 
- Isothermal surfaces are parallel to the ground.

- The terrain slope is uniform in a single set-up of the instrument.

\section{National leveling network first order}

Bulgarian national leveling network first order is part of the United European Leveling Network (UELN) (Belyashki, 2004; Sacher et al., 2004). Leveling lines are with average length of about $109 \mathrm{~km}$. In all previous measurement refraction correction was not applied in the estimation. In the next cycle it is foreseen to be included. For that reason it is necessary to perform a study to obtain refraction correction with real leveling and temperature measurements of at least one leveling line to estimate what will be the results in every set-up, leveling distances, whole leveling line and the influence in the error estimation. The results presented in this study will be of interest to other countries, which will include a refraction correction in theirs national leveling networks.

For this study, the leveling measurements provided by Geodesy, Cartography and Cadastre Agency were used. The measurements cover one whole leveling line with length $109 \mathrm{~km}$ (Figure 1).

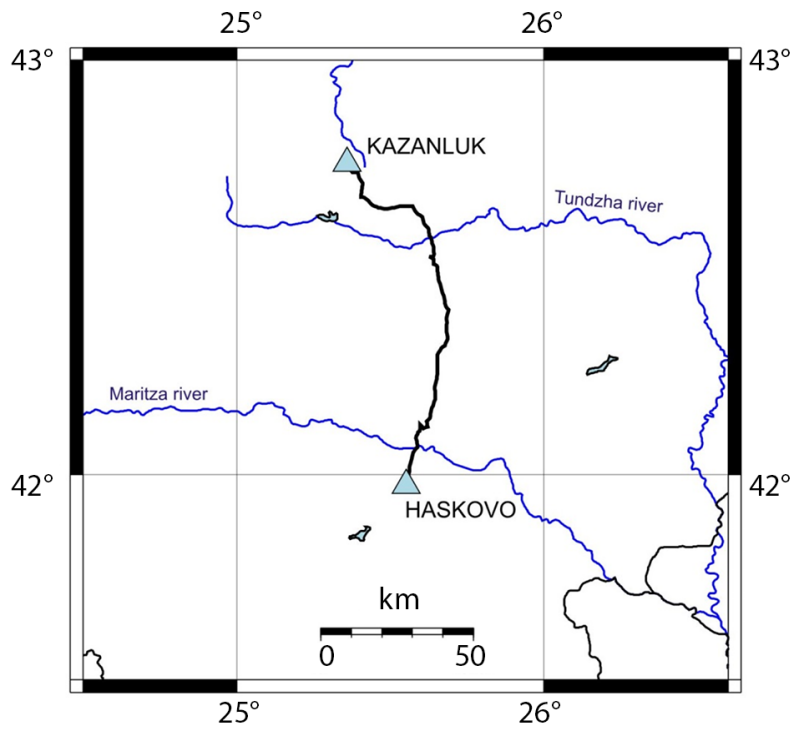

Figure 1. First order leveling line Kazanluk - Haskovo

The leveling line consists of 89 leveling distances, measured two times, fore and back with 2267 and 2243 set-ups respectively. The measurements were made with a precise digital level Sokkia SDL 1X with couple invar rods. For every leveling distance difference in elevation $d$, between fore and back leveling, is calculated. The accepted limit is:

$$
d \leq \pm 1.5 \sqrt{S_{k m}},
$$

where: $S$ is the length of leveling distance in $\mathrm{km} ; d$ is obtained in $\mathrm{mm}$.

Root mean square $m$ for $1 \mathrm{~km}$ leveling, obtained by differences of elevation from fore and back leveling is:

$$
m= \pm \frac{1}{2} \sqrt{\frac{1}{n}\left[\frac{d^{2}}{S}\right]},
$$

where: $n$ is number of leveling distances; $d$ and $S$ has the same meaning as in (3) and the accepted limit is $\pm 0.40 \mathrm{~mm}$.

The results of the estimation show that the all $d$ in (3) are in the limit, sum of $d=27.61 \mathrm{~mm}$ and root mean square $m= \pm 0.39 \mathrm{~mm}$.

Simultaneously with the leveling, the air temperatures were measured in each set-up in every rode at heights of $0.5 \mathrm{~m}, 1.5 \mathrm{~m}$ and $2.5 \mathrm{~m}$. Digital thermometers are used, the sensors are attached to the back of the rods and are protected from direct sunlight.

\section{Data processing and results}

The measured temperatures are checked in order to be acceptable, the temperature differences between the upper and lower thermometer of the rods should be between $-3.0^{\circ} \mathrm{C}$ and $+1.0^{\circ} \mathrm{C}$ (Murray, 1999). Also the difference between the temperature differences of two successive setups should be between $-3.0^{\circ} \mathrm{C}$ and $+3.0^{\circ} \mathrm{C}$ (Murray, 1999). When the temperature measurements meet this requirements the average of temperature differences between upper and lower thermometer in back and for rode are used. In several leveling distances one of the thermometers has failed and did not meet the requirements. In this case only temperature differences measured on one rode is used.

Refraction correction $\mathrm{R}$ is calculated for every set-up and it's sum for every leveling distance is obtained too. For the predetermined coefficient $\mathrm{A}$ in (1) a value of 70 is used.

On Figure 2 and Figure 3 the values of refraction correction for every set-up along the line in fore and back leveling are shown along with cross section of the leveling line.

On Figure 4 and Figure 5 the refraction correction values for every leveling distance are given for fore and back leveling respectively.

After applying the calculated refraction correction in estimation it is observed that the difference in elevation $\mathrm{d}$ for every leveling distance remains in the limit (3), in 51 leveling distances it is become smaller in absolute value and the sum of $d=25.89 \mathrm{~mm}$. Root mean square $\mathrm{m}$ for 1 $\mathrm{km}$ leveling, obtained by differences of elevation from fore and back leveling is $m= \pm 0.37 \mathrm{~mm}$.

\section{Discusions}

The obtained values for refraction correction for the every set-up varies mostly between $-0.2 \mathrm{~mm}$ and $+0.2 \mathrm{~mm}$ and for every leveling distance varies between $-0.8 \mathrm{~mm}$ and $+0.6 \mathrm{~mm}$. From Figure 2, and Figure 3 it is clearly visible that largest values of refraction correction are observed when the leveling line pass through highest terrain slope. 


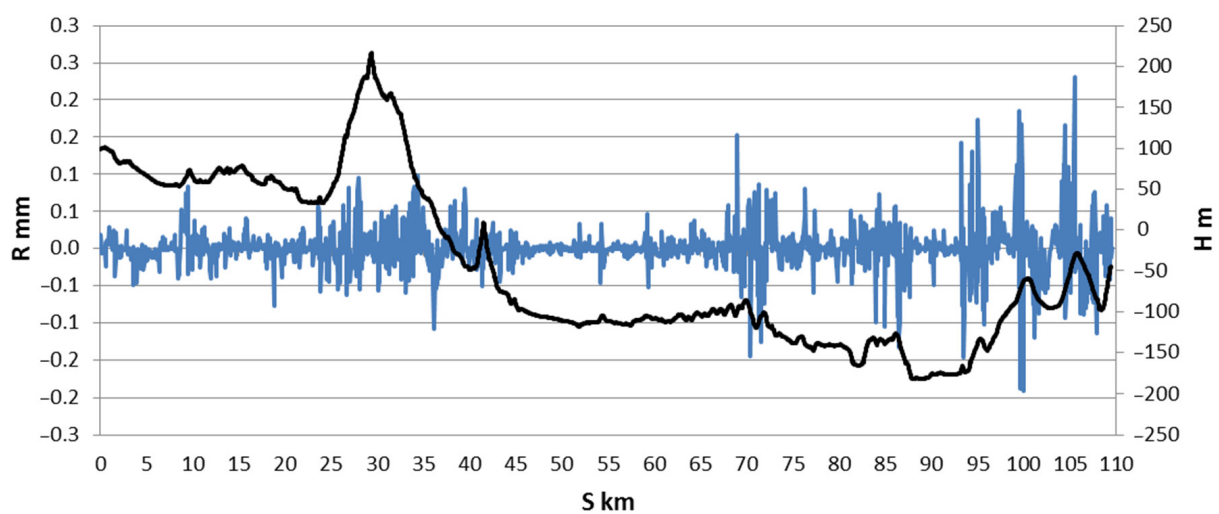

Figure 2. Refraction correction calculated for every set-up in fore leveling in blue and cross section of the leveling line in black

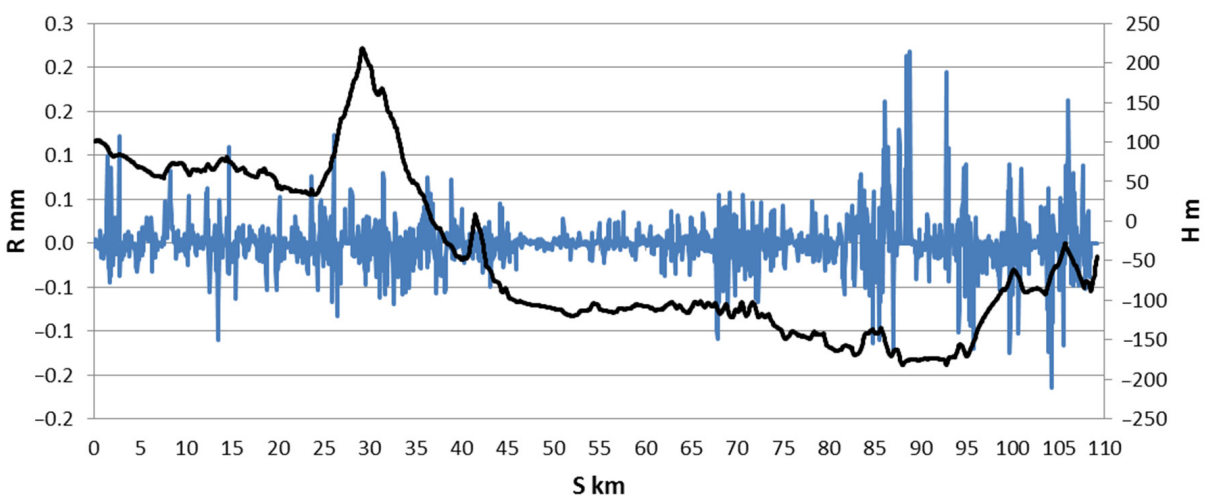

Figure 3. Refraction correction calculated for every set-up in back leveling in blue and cross section of the leveling line in black

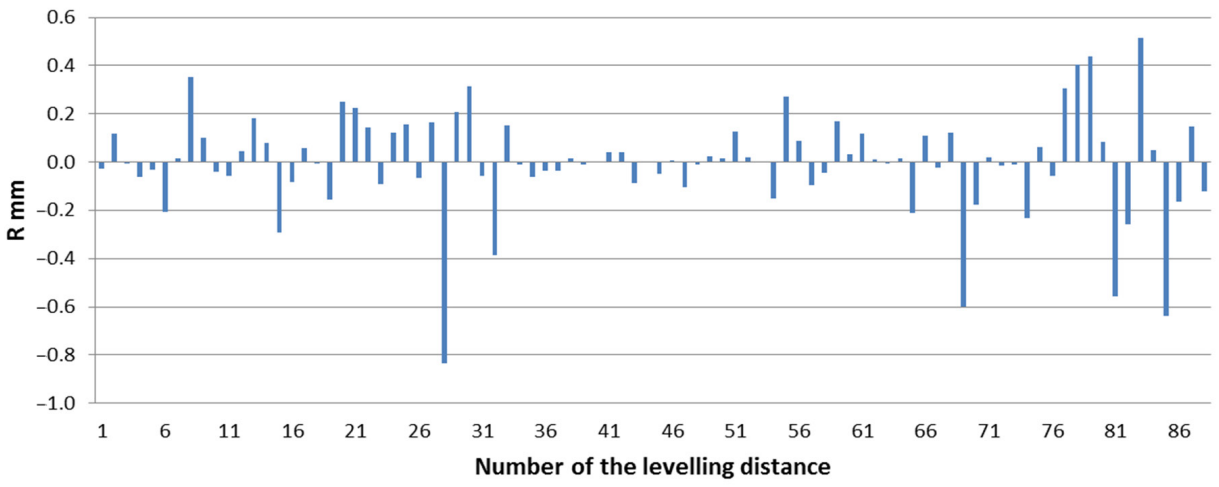

Figure 4. Refraction correction values for every leveling distance in fore leveling

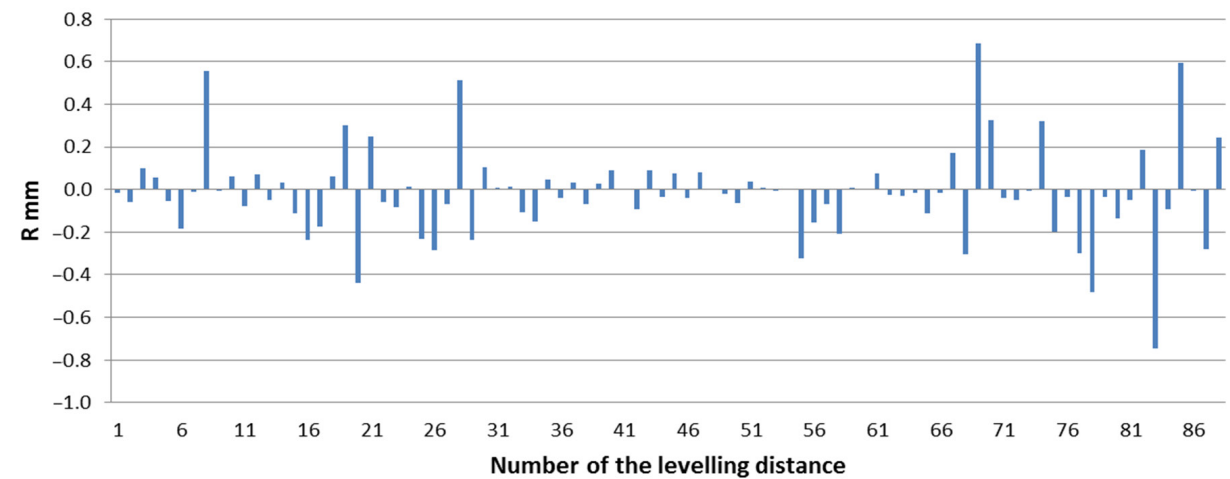

Figure 5. Refraction correction values for every leveling distance in back leveling 
When the leveling line is almost flat the value of refraction correction is close to zero. The error caused by atmospheric refraction is not compensated when leveling successive distances with positive and negative difference of elevation. For example, for the length from $\mathrm{km} 25.29$ to $\mathrm{km} 34.3$ (Figure 3 and Figure 4), where the line crosses mountain hill with height of about $160 \mathrm{~m}$ and goes back to the same elevation the sum of refraction correction value is $1.18 \mathrm{~mm}$ in fore leveling and $0.27 \mathrm{~mm}$ in back leveling. As it is expected the refraction is grater on sight close to surface, so, the rode reading on that sight that is close to the terrain is more affected then other because goes through more isothermal air layers (Angus-Leppan, 1884).

The precision of measured temperatures gives a significant impact on the value of the refraction correction. Numerous meteorological publications show that in the night the ground is colder than the air just above it. Soon after the sunrise temperature of the air is decreasing with the height and the temperature of the ground becomes higher than the temperature of the air just above it. For this reason the temperature gradient is negative at day and positive at night. The absolute values of the vertical gradient should be greater in the clear sky, day or night (Kukkamäki, 1978).

Inaccurate measured temperature could be the reason why not all difference in elevation $d$, for every leveling distance, not become smaller in absolute value as it is expected. Other reason for that could be because the value of predetermined coefficient $A=70$ is not appropriate for the territory of Bulgaria. It is recommended to perform experimental research and to develop a model for the vertical refraction that is suitable for the territory of Bulgaria.

\section{Conclusions}

The results obtained show that the refraction correction is commensurable with rod scale correction. This correction must be applied for each set-up and it is not eliminated with the same positive and negative differences of elevation. The largest values of refraction correction are observed in the leveling distances with highest terrain slope.

Measurements of the temperature should be done simultaneously with leveling by aspiration thermometers (with forced air flow) to obtain maximum reliable temperature gradient values. Thermometer readings should be monitored and evaluated. In order to be acceptable, the temperature differences between the upper and lower thermometer of the rods should be between $-3.0{ }^{\circ} \mathrm{C}$ and $+1.0^{\circ} \mathrm{C}$. Also the difference between the temperature differences of two successive set-ups should be between $-3.0{ }^{\circ} \mathrm{C}$ and $+3.0{ }^{\circ} \mathrm{C}$. If the measured temperatures are outside these limits, it is recommended not to conduct leveling measurements until the cause is eliminated or the weather conditions are improved.

It is recommended to perform experimental research and to develop a model for the vertical refraction that is suitable for the territory of Bulgaria. The applying of the refraction correction does not eliminates the requirements associated with balancing of the length of sights, maximum length of sight, minimum high of sight, and the choice of appropriate weather conditions.

\section{Acknowledgements}

Acknowledgements to Bulgarian Geodesy, Cartography and Cadastre Agency for provided data of leveling measurements that covers one whole leveling line with length $109 \mathrm{~km}$.

\section{Funding}

No funding.

\section{Author contributions}

All authors have the same contributions.

\section{Disclosure statement}

No financial, professional, or personal interests from other parties.

\section{References}

Angus-Leppan, P. V. (1884). Refraction in geodetic levelling. In F. K. Brunner (Ed.), Geodetic refraction. Springer. https://doi.org/10.1007/978-3-642-45583-4_8

Belyashki, T. (2004). Connecting the state levelling network of Bulgaria with the United European Levelling Network (UELN). Geodesy, Cartography, Land Surveying, 5-6, 3-5 (in Bulgarian).

Holdahl, S. R. (1981). A model of temperature stratification for correction of levelling refraction. In NOAA Technical Memorandum (NOS NGS 31). Rockville, Md.

https://www.ngs.noaa.gov/PUBS_LIB/AModelOfTemperatureStratificationForCorrectionOfLevelingRefraction_TM_ NOS_NGS31.pdf

Hytonen, E. (1967). Measuring of the refraction in the second levelling of Finland. In Publication of the Finnish Geodetic Institute (No. 63). Helsinki, Finland.

Kukkamäki, T. J. (1939). Formulas and tables for computation of leveling refraction. In Publication of Geodetic Institute (No. 27). Helsinki, Finland.

Kukkamäki, T. J. (1978). Leveling refraction research, its present state and future possibilities. Symposium - International

Astronomical Union, 89, 293-299. https://doi.org/10.1017/S0074180900066110

Murray, O. W. (1999). Digital leveling user's guide. NOAA. https://topografiaepcc.unex.es/wp-content/uploads/2018/02/ Guide_leica_na3003.pdf

Sacher, M., Belyashki, T., Liebsch, G., \& Ihde, J. (2004). Status of the UELN/EVRS database and results of the last UELN adjustment. Symposium of the IAG Subcommission for Europe (EUREF) held in Bratislava, 29(12), 232-235. 